\title{
The Maastricht Study: an extensive phenotyping study on determinants of type 2 diabetes, its complications and its comorbidities
}

Citation for published version (APA):

Schram, M. T., Sep, S. J. S., van der Kallen, C. J., Dagnelie, P. C., Koster, A., Schaper, N., Henry, R. M. A., \& Stehouwer, C. D. A. (2014). The Maastricht Study: an extensive phenotyping study on determinants of type 2 diabetes, its complications and its comorbidities. European Journal of Epidemiology, 29(6), 439451. https://doi.org/10.1007/s10654-014-9889-0

Document status and date:

Published: 23/04/2014

DOI:

10.1007/s10654-014-9889-0

Document Version:

Publisher's PDF, also known as Version of record

Document license:

Taverne

Please check the document version of this publication:

- A submitted manuscript is the version of the article upon submission and before peer-review. There can be important differences between the submitted version and the official published version of record.

People interested in the research are advised to contact the author for the final version of the publication, or visit the DOI to the publisher's website.

- The final author version and the galley proof are versions of the publication after peer review.

- The final published version features the final layout of the paper including the volume, issue and page numbers.

Link to publication

\footnotetext{
General rights rights.

- You may freely distribute the URL identifying the publication in the public portal. please follow below link for the End User Agreement:

www.umlib.nl/taverne-license

Take down policy

If you believe that this document breaches copyright please contact us at:

repository@maastrichtuniversity.nl

providing details and we will investigate your claim.
}

Copyright and moral rights for the publications made accessible in the public portal are retained by the authors and/or other copyright owners and it is a condition of accessing publications that users recognise and abide by the legal requirements associated with these

- Users may download and print one copy of any publication from the public portal for the purpose of private study or research.

- You may not further distribute the material or use it for any profit-making activity or commercial gain

If the publication is distributed under the terms of Article $25 \mathrm{fa}$ of the Dutch Copyright Act, indicated by the "Taverne" license above, 


\title{
The Maastricht Study: an extensive phenotyping study on determinants of type 2 diabetes, its complications and its comorbidities
}

\author{
Miranda T. Schram • Simone J. S. Sep • Carla J. van der Kallen • \\ Pieter C. Dagnelie • Annemarie Koster • Nicolaas Schaper • \\ Ronald M. A. Henry • Coen D. A. Stehouwer
}

Received: 19 August 2013/Accepted: 13 March 2014/Published online: 23 April 2014

(C) Springer Science+Business Media Dordrecht 2014

\begin{abstract}
The Maastricht Study is an extensive phenotyping study that focuses on the etiology of type 2 diabetes (T2DM), its classic complications, and its emerging comorbidities. The study uses state-of-the-art imaging techniques and extensive biobanking to determine health status in a population-based cohort of 10,000 individuals that is enriched with T2DM individuals. Enrollment started in November 2010 and is anticipated to last 5-7 years. The Maastricht Study is expected to become one of the most extensive phenotyping studies
\end{abstract}

On behalf of the Maastricht Study Group.

Electronic supplementary material The online version of this article (doi:10.1007/s10654-014-9889-0) contains supplementary material, which is available to authorized users.

M. T. Schram ( $₫)$. S. J. S. Sep · C. J. van der Kallen .

N. Schaper · R. M. A. Henry - C. D. A. Stehouwer

Department of Medicine, Maastricht University Medical

Center+, Randwycksingel 35, 6229 EG Maastricht,

The Netherlands

e-mail: m.schram@maastrichtuniversity.nl

M. T. Schram · S. J. S. Sep · C. J. van der Kallen

P. C. Dagnelie - N. Schaper - R. M. A. Henry ·

C. D. A. Stehouwer

Cardiovascular Research Institute Maastricht (CARIM),

Maastricht University, Maastricht, The Netherlands

P. C. Dagnelie

Department of Epidemiology, Maastricht University, Maastricht,

The Netherlands

P. C. Dagnelie - A. Koster - N. Schaper - C. D. A. Stehouwer

School for Public Health and Primary Care (CAPHRI),

Maastricht University, Maastricht, The Netherlands

A. Koster

Department of Social Medicine, Maastricht University,

Maastricht, The Netherlands in both the general population and T2DM participants worldwide. The Maastricht study will specifically focus on possible mechanisms that may explain why T2DM accelerates the development and progression of classic complications, such as cardiovascular disease, retinopathy, neuropathy and nephropathy and of emerging comorbidities, such as cognitive decline, depression, and gastrointestinal, musculoskeletal and respiratory diseases. In addition, it will also examine the association of these variables with quality of life and use of health care resources. This paper describes the rationale, overall study design, recruitment strategy and methods of basic measurements, and gives an overview of all measurements that are performed within The Maastricht Study.

Keywords Cardiovascular disease $\cdot$ Chronic disease Comorbidity · Pathophysiology · Prospective cohort study · Study design - Type 2 diabetes

\begin{tabular}{|c|c|}
\hline \multicolumn{2}{|c|}{ Abbreviations } \\
\hline AGEs & Advanced glycation end products \\
\hline ATC-code & $\begin{array}{l}\text { Anatomical therapeutic chemical } \\
\text { classification system }\end{array}$ \\
\hline DVA & Dynamic vessel analysis \\
\hline ECG & Electrocardiogram \\
\hline EMG & Electromyogram \\
\hline HR-pQCT & $\begin{array}{l}\text { High resolution peripheral quantitative } \\
\text { computed tomography }\end{array}$ \\
\hline IFG & Impaired fasting glucose \\
\hline IGT & Impaired glucose tolerance \\
\hline MVPA & Moderate-to-vigorous physical activity \\
\hline NGT & Normal glucose tolerance \\
\hline OCT & Optical coherence tomography \\
\hline OGTT & Oral glucose tolerance test \\
\hline T2DM & Type 2 diabetes mellitus \\
\hline VFA & Vertebral fracture assessment \\
\hline
\end{tabular}




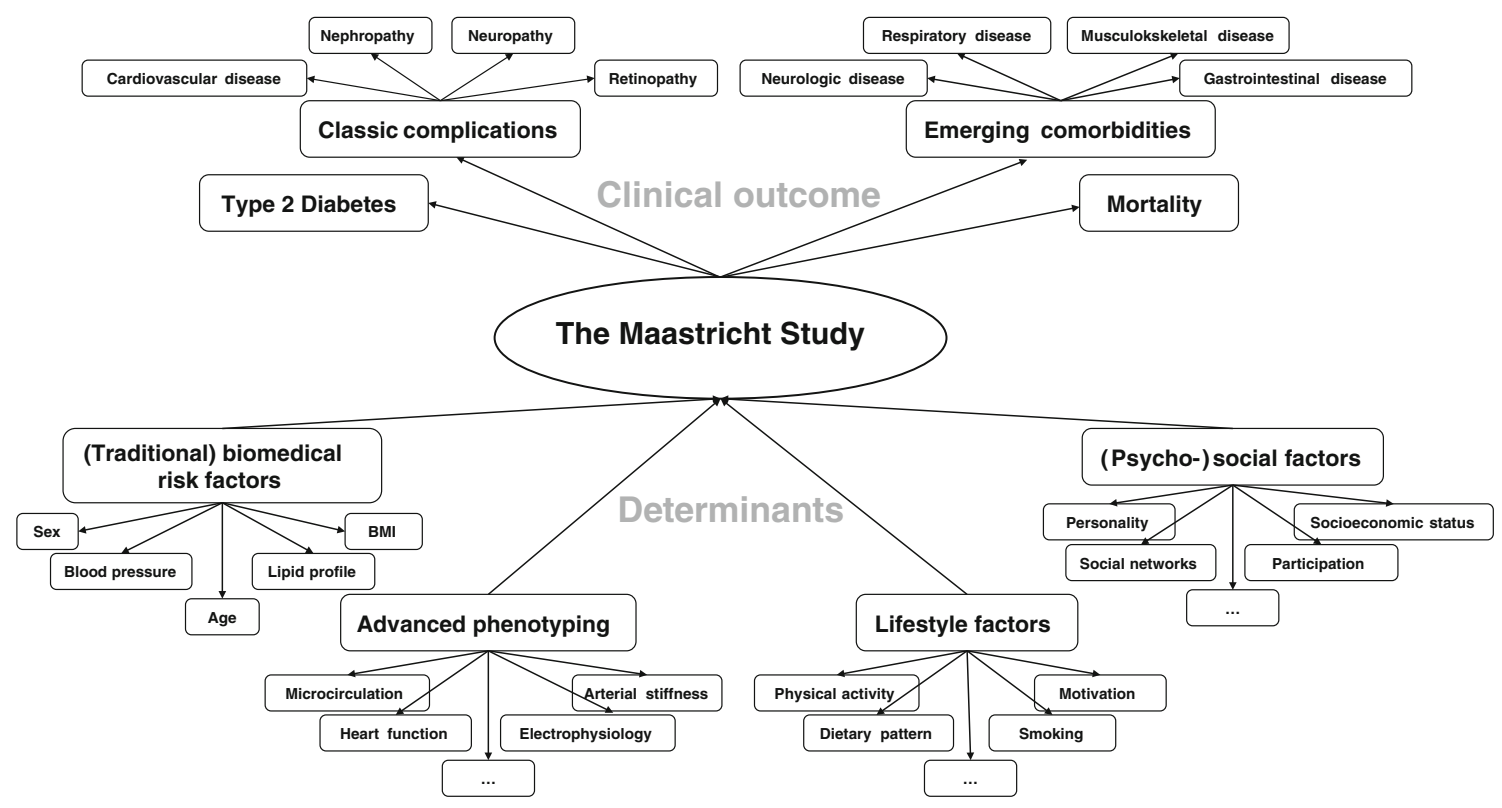

Fig. 1 An advanced phenotyping approach is applied to all participants of The Maastricht Study. The bottom of the figure shows main categories of determinants that are measured. The top of the figure presents the main clinical outcomes that are studied

\section{Introduction}

Although in past decades much information has been gathered on the pathogenetic pathways of type 2 diabetes (T2DM) and its complications, these mechanisms are frequently studied in isolation. Moreover, T2DM is closely associated with numerous other comorbidities, and again, these associations are mainly studied in isolation. In this paper we describe the background, rationale and design of The Maastricht Study, which aims to study the etiology and pathophysiology of type 2 diabetes (T2DM), its classic complications and its emerging comorbidities in relation to each other by use of an extensive phenotyping approach. Figure 1 illustrates the advanced phenotyping approach of The Maastricht Study.

T2DM has become a major global health challenge of the twenty first century. In 2000 the total number of T2DM was estimated at 171 million individuals world-wide, and it is expected to rise to 366 million in 2030 [1]. Diabetes is ranked fifth on the scale of non-communicable diseases that cost most (healthy) life years [2, 3]. Individuals diagnosed with T2DM will lose 16-18 quality-adjusted life-years due to diabetes [4, 5], and will die, on average, 6 years earlier than their counterparts without diabetes [6]. In addition, treatment of diabetes is costly. Of these costs $50 \%$ is attributed to diabetes treatment itself, and $50 \%$ to the treatment of complications [7]. Although the development of new drugs and a holistic treatment approach have improved diabetes care, further improvement of the prognosis and quality of life of individuals with T2DM remains important, as there is still much to gain.

The central pathophysiological features of T2DM are insulin resistance and beta cell dysfunction [8-10]. Much information has been obtained on the genetic and (individual) environmental risk factors of the disease in the past decades. However, detailed information on the pathophysiologic mechanisms and the interaction of risk factors is scarce. In addition, known risk factors cannot fully explain the development of T2DM, suggesting that new risk factors await discovery.

New, in-depth knowledge is urgently needed in order to prevent the development of classic complications and the emerging comorbidities of T2DM. In developed countries, T2DM at least doubles the risk of cardiovascular disease, is the leading cause of blindness, and is responsible for over $40 \%$ of end-stage renal failure and over $60 \%$ of nontraumatic lower-limb amputations [11-15]. Next, there is growing evidence that T2DM accelerates the development and progression of other chronic diseases, in addition to the classic complications of T2DM [6]. Mortality due to these emerging comorbidities is about $70 \%$ higher in T2DM compared to individuals without T2DM [6]. Why other chronic diseases like dementia, depression and chronic obstructive pulmonary disease (COPD), cluster with T2DM is unclear. Possible hypotheses are that these different disease states are caused by common determinants (e.g., chronic inflammation), by features of T2DM itself (e.g., microvascular dysfunction), and/or affect each other by reversed causality (i.e., the comorbid condition contributes to the development of T2DM).

The Maastricht Study: rationale and aims

Taken together, detailed epidemiological studies combining extensive phenotyping with a focus on a broad range of 
determinants (including extensive -omics) are urgently needed to elucidate the complex underlying pathophysiology of T2DM and the interaction with other chronic diseases. This requires not only a large population-based subset of T2DM patients, but also a population-based cohort of individuals without T2DM and individuals at high risk to develop T2DM. Such studies are currently not available and The Maastricht Study intends to fill this gap. It aims to identify determinants of the development and progression of (a) T2DM; (b) its classic complications (cardiovascular disease, retinopathy, neuropathy and nephropathy); and (c) its emerging comorbidities, such as cognitive decline, depression, and gastrointestinal, musculoskeletal and respiratory diseases. In addition, the impact of this clustering of comorbidities on quality of life and use of health care resources will be defined. The Maastricht Study is expected to become one of the most extensive phenotyping studies in both the general population and T2DM participants world-wide.

\section{Examples of in-depth phenotyping approaches}

In the following paragraphs, we present four research concepts with regard to biobanking, advanced cardiovascular imaging, lifestyle and (psycho-)social factors that are included in The Maastricht Study as examples of the type of research that is achievable in this study.

\section{Biobanking}

Risk stratification in clinical practice is currently inefficient because of the lack of biomarkers that can accurately predict the development of chronic diseases and their complications. For example, the numbers needed to treat in cardiovascular risk management currently range from 20 for antihypertensive treatment up to 100 individuals for statin treatment per 5 years $[16,17]$. Improvement of these figures will tremendously increase the efficiency of care. In order to achieve this, novel biomarkers that can accurately identify individuals at high risk are needed. Moreover, recent technological advances in genetics, genomics, proteomics, and bioinformatics offer a vast opportunity for biomarker discovery. Therefore, extensive biobanking for the identification of novel and innovative biomarkers is an important feature of The Maastricht Study.

\section{Advanced cardiovascular imaging}

The increased cardiovascular risk in T2DM [18] is only partly explained by the excess prevalence of traditional cardiovascular risk factors, such as hypertension, dyslipidemia, obesity and inflammation. It is therefore likely that other pathophysiological mechanisms are involved. We aim to identify the early structural and functional changes in the arterial vessel wall and heart that lead to arterial stiffness, and diastolic and systolic dysfunction. Next, the electrophysiology of the heart is studied comprehensively. In addition, as microvascular dysfunction may be a major contributor to myocardial damage and is a hall-mark feature of T2DM, we will extensively assess microcirculatory structure and function. Investigation of this broad range of cardiovascular biomarkers will help us to elucidate the specific contribution of these novel markers to the development of cardiovascular disease in individuals with and without T2DM.

\section{Lifestyle factors}

Lifestyle factors, such as smoking, diet, and physical activity are known to play an important role in the development and progression of T2DM. In the past decades, the amount of time that people spend sitting has dramatically increased in all age groups. Although the health benefit of participation in moderate-to-vigorous physical activity (MVPA) has long been acknowledged [19, 20], the negative impact of co-existing sedentary time has, until recently, been largely neglected. Recent studies have suggested that sedentary behavior plays a major role in the development and progression of cardio-metabolic conditions independent of MVPA [21, 22]. Most evidence so far, however, comes from studies with self-reported sedentary time. Only recently a limited number of studies using objectively measured sedentary behavior data have shown that sedentary behavior is an important health risk factor independent of MVPA [23-26]. The objective measurement of physical activity by accelerometry will allow us to address the following research questions: 1) do patterns of daily activity, and in particular the amount of sedentary time, differ across the glucose tolerance spectrum; 2) is sedentary behavior associated with prevalence and incident (pre)diabetes and if so, is this association independent of MVPA; and 3) is sedentary behavior associated with the prevalence and incidence of the classic complications and emerging comorbidities of T2DM?

\section{(Psycho-)social factors}

In addition to biomedical and lifestyle factors, socioeconomic and psychosocial factors, personality and social networks are probably important determinants in the development and progression of T2DM and other chronic diseases. For example, individuals with a low SES do not only live shorter than their better-off counterparts; they also live a greater proportion of their lives in poor health [27]. In addition, the prevalence of T2DM is higher in low SES groups across many countries [28]. In The Maastricht 
Fig. 2 Age and sex distribution of the population between 40 and 75 years of age living in the study region $(\mathrm{n}=82,462)$

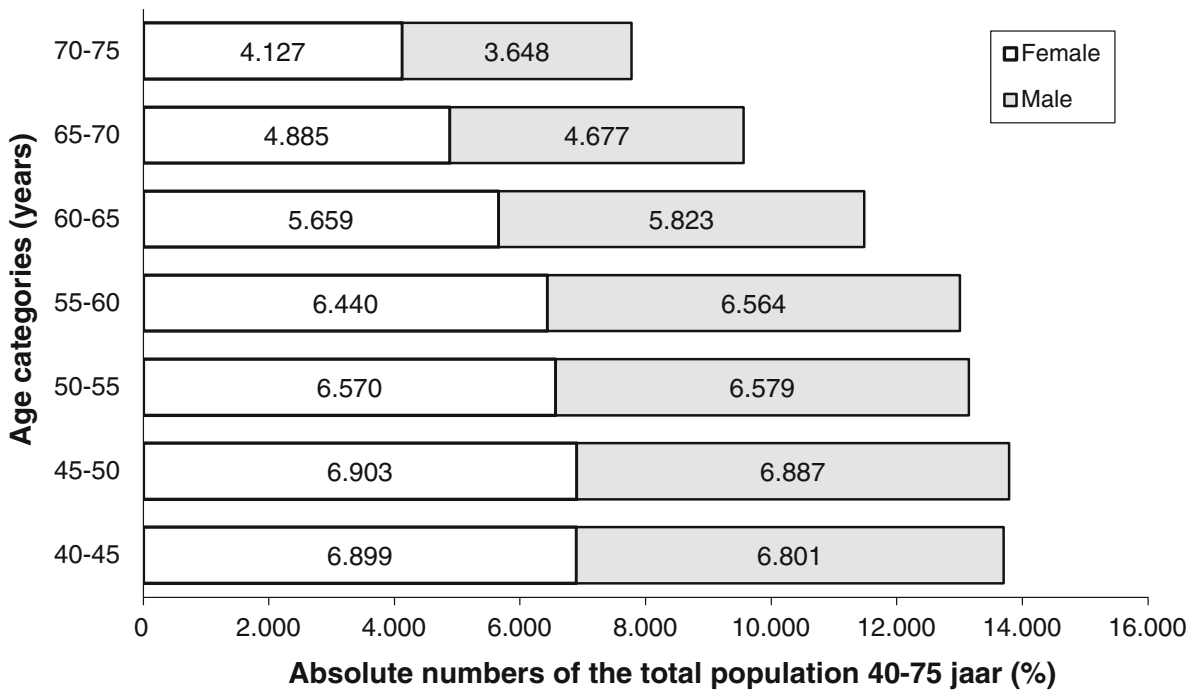

Study we will be able to unravel the mechanisms underlying the interrelationships between (life-course) SES and T2DM, its classic complications and subsequent quality of life.

\section{Materials and methods}

Study design, inclusion criteria and study area

The Maastricht Study is an observational prospective population-based cohort study enriched with T2DM individuals that aims to include 10,000 participants. Eligible for participation are all individuals aged between 40 and 75 years and living in the southern part of the Netherlands (municipalities Maastricht, Margraten-Eijsden, Meersen and Valkenburg; Maastricht and Heuvelland in the province of Limburg). The study population will be enriched with T2DM participants for reasons of efficiency; i.e., to increase the statistical power to identify any potential contrasts between individuals with and without T2DM. The Maastricht Study started with an initial survey in November 2010, which is anticipated to last 5-7 years. Subsequent surveys are planned, conditional on funding. An annual follow-up on disease incidence and mortality is in progress.

The study area is defined by postal codes. Approximately $60 \%$ of the population lives in an urban setting (the city of Maastricht, 120,000 inhabitants, 2,088 inhabitants per $\mathrm{km}^{2}$ ) and $\sim 40 \%$ lives in a suburban/rural setting (in the three villages surrounding Maastricht: 17,000-24,000 inhabitants, 319-721 inhabitants per $\mathrm{km}^{2}$ ). The study area encloses 82,462 inhabitants aged 40-75 years, including an estimated 7,000 individuals with T2DM. The target population comprises slightly more women than men (41,483 women vs. 40,979 men) and includes mainly Caucasians.
Figure 2 illustrates the age distribution of the population as well as the male to female ratio. Employments are mainly in industry $(20 \%)$, business $(17 \%)$, health care $(16 \%)$ and business services (13\%).

\section{Recruitment strategy}

Participants are recruited from mass media campaigns and from the municipal registries (Gemeentelijke Basis Administratie; GBA) and the regional Diabetes Patient Registry (see below) via mailings. The representation with the source population in the study region is monitored continuously (see Fig. 3) and is aligned with postal codes.

The regional Diabetes Patient Registry is kept by the regional association of General Practitioners (Zorg in Ontwikkeling (ZIO)) and the Maastricht University Medical Centre. This registry includes individuals that apply to their GP with health complaints which lead to the diagnosis of T2DM, and individuals that are diagnosed with T2DM after cardiovascular screening. The registry virtually includes all T2DM individuals in primary, secondary or tertiary medical care in the "Maastricht and Heuvelland" region.

Ethical considerations, patient information and written informed consent

The study has been approved by the institutional medical ethical committee (NL31329.068.10) and the Netherlands Health Council under the Dutch "Law for Population Studies" (Permit 131088-105234-PG). Study information including an informed consent form is sent to all participants by mail prior to the study visits. An oral explanation on study procedures is provided and the informed consent form is signed. The informed consent form includes specific items on biobanking, genetic analysis, and linkage to medical databases and important national databases like the 
Fig. 3 Recruitment process of study participants

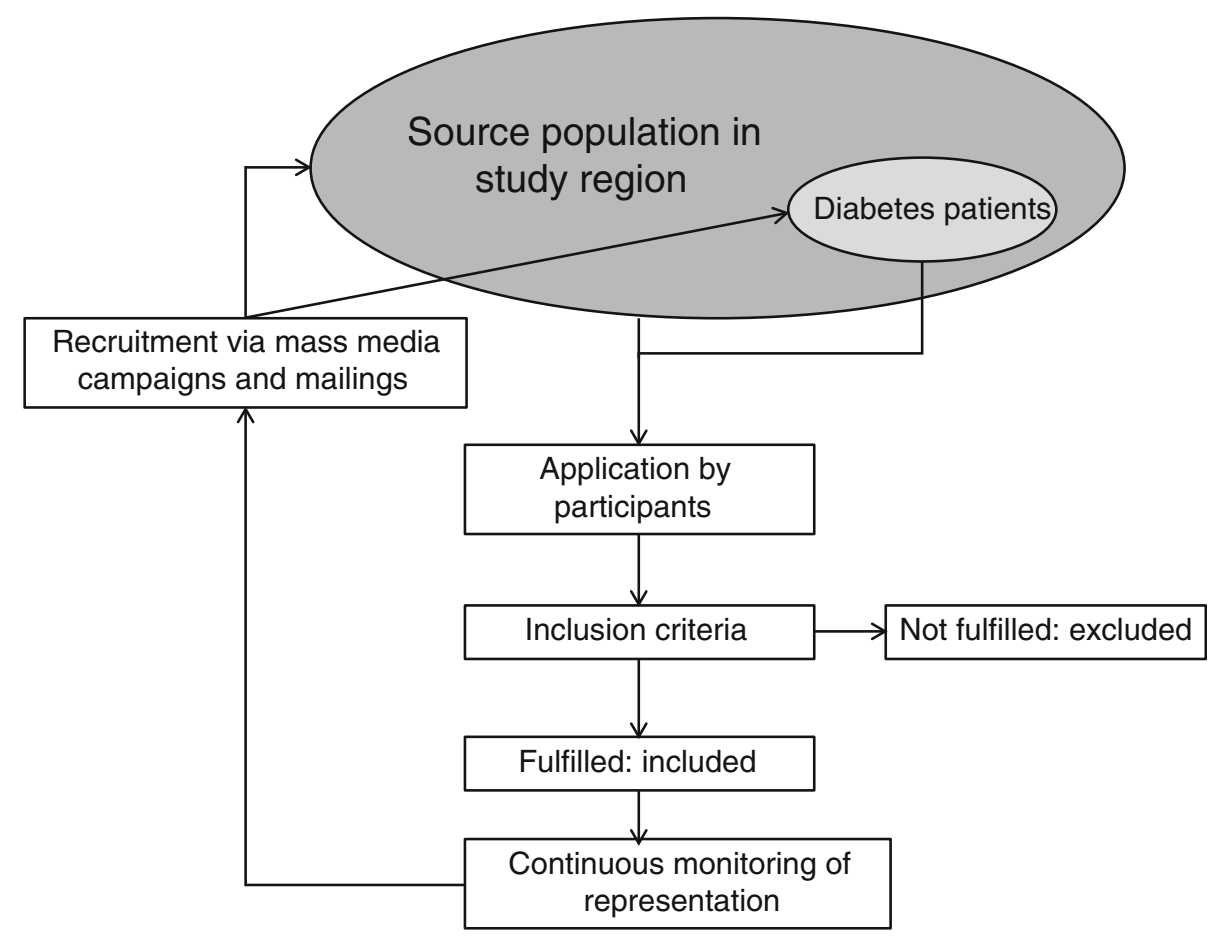

municipality register, and the national database for mortality follow-up. Furthermore, the informed consent form includes a paragraph on incidental findings and the option to refuse to be informed about any unexpected abnormalities. Participants who agreed to be informed and have incidental findings that require follow-up evaluation or treatment are referred to appropriate specialists via their general practitioner. Individuals that are unable to understand, read, and write the Dutch language are excluded because they cannot provide written informed consent.

Data collection

All measurements are performed by trained research assistants during three to four 4-h visits to The Maastricht Study research center using standardized protocols. In principle, all procedures apply to all participants included, unless clinically contraindicated. The full examination of each participant finishes within a time window of 3 months. At the final examination day an exit interview with a physician is carried out where results of the following measurements are communicated to the participant: body mass index, $24 \mathrm{~h}$ blood pressure, glucose and cholesterol levels, lung function, kidney function, ankle brachial index, heart function based on ultrasound and ECG, cognitive function, depressive symptoms, fundus photography and hearing. In addition, the cardiovascular risk score based on a Dutch modification of the Framingham Risk score [29] is calculated.
The collected data are filed on written forms or directly entered into the electronic database. The written forms are entered in duplicate into the electronic dataset to monitor the quality of the data entry process. All questionnaires are filled-in by participants via a web-based questionnaire program, initially under supervision at the research center and thereafter, if feasible, at home. Trained staff members at the research center provide additional instructions and assistance to participants if needed. The total amount of time needed to fill in all questionnaires approximates $3 \mathrm{~h}$. Questionnaires are presented in eight parts of 20-30 min each. The first two parts are filled in at the research center, during the first site visit. The other parts are completed at home, in between site visits. Adherence is checked at each site visit and finally during the exit interview.

The following section describes the measurements performed within The Maastricht Study. Table 1 gives an overview of the data collection, specified according to general and disease-specific measurements. Detailed protocols of the general measurements are presented in the supplemental material. More advanced measurements are mentioned briefly and will be described in subsequent papers in more detail.

General data collection

\section{Laboratory assessments}

Fasting blood samples, two $24 \mathrm{~h}$ urine samples and morning urine samples are collected for laboratory 
Table 1 General and disease-specific measurements within the Maastricht Study

\section{General measurements}

Laboratory assessments

Fasting levels of glucose, total cholesterol, LDL- and HDL cholesterol, triglycerides, albumin, creatinine, uric acid, $\mathrm{HbA} 1 \mathrm{c}$, hemoglobin, hematocrit, red blood cell count, leukocyte and platelet count, mean platelet volume

$24 \mathrm{~h}$ urine levels of albumin, creatinine and uric acid

Spot urine levels of glucose and nitrite (dipstick), albumin, creatinine, red blood cell and leukocyte count

Physical examination

Anthropometry: height, weight, circumference measures of waist, hip, upper arm, calf, and wrist, and biceps, triceps, suprailiac, and subscapular skinfold measurements and bioelectrical impedance

Physical function and performance

6 Minutes fast walk test, timed stand chair test, submaximal exercise capacity test by bicycle, isometric strength of arms and legs, and hand grip strength

Medication use

Medication interview

Blood pressure

Blood pressure: office, 24-hr ambulatory and 7 days home blood pressure

General questionnaires

Medical history, family history of diabetes and cardiovascular disease, socioeconomic status, smoking behavior, physical activity, alcohol consumption, quality of life, activities of daily living, birth weight, ethnicity and economic evaluation

Biobanking

Fasting serum, EDTA, citrated, acified citrated, heparin and protease inhibitor containing plasma samples

EDTA whole blood sample and Paxgene tube for DNA and RNA extraction

Two times $24 \mathrm{~h}$ and one spot urine samples

Serum, EDTA and citrate plasma sampled at time points 15, 30, 45, 60, 60, 90 and 120 min during OGTT

\section{T2DM and its classic complications}

Physical examinations: Type 2 diabetes

7-point oral glucose tolerance test (OGTT)

Skin autofluerescence for the assessment of advanced glycation end products in the skin

Physical examinations: cardiovascular disease

12-leads ECG, $24 \mathrm{~h}$ ambulatory ECG and ankle-brachial index

Physical examinations: retinopathy

Fundusphotograpy

Physical examinations: nephropathy

Spot and $2 \times 24 \mathrm{~h}$ urine collections to assess micro- and macroalbuminuria, eGFR

Physical examinations: Neuropathy

Neurothesiometry

Disease specific questionnaires

Rose questionnaire, DN4, PAID and hypoglycemia

Advanced measurements
Table 1 continued

Microvascular assessment, vascular ultrasound \& applanation tonometry, cardiac ultrasound, autonomic function test, 178 channel high resolution surface ECG, EMG assessment, ECG guided exercise test, abdominal fat (ultrasound)

\section{Emerging comorbidities of T2DM}

\section{Neurological diseases}

Interview and physical examinations

Cognitive testing: MMSE, GIT wordlist, 15-Word Learning Test including delayed recall and recognition, Stroop test, Concept Shifting Test, Letter-Digit Substitution Test, Fluency test, CAMDEX when indicated

Depression: mini interview (depression, suicide, anxiety)

Hearing check

Disease specific questionnaires

PHQ-9, GAD-7, Migraine screening questionnaire, Migraine Disability Assessment (MIDAS) questionnaire, Hearing Handicap Inventory for the Elderly screening questionnaire, International Outcome Inventory for Hearing Aids, mini Tinnitus questionnaire, and questionnaires on forgetfullness and presence of eye disease.

Advanced measurements

Eye diseases; visual acuity, optical coherence tomography, ocular pressure, Scheimpflug analysis, perimetry, corneal confocal microscopy, macula pigmentation and dynamic vessel analysis

\section{Respiratory diseases}

Physical examinations

Spirometry, ambulatory sleep disordered breathing, nose and throat swabs, collection of exhaled breath samples to analyse volatile organic compounds

Disease specific questionnaires

American Thoracic Society (ATS-DLD78), Epworth Sleepiness Scale, nicotine dependence and quit smoking, acute infections

\section{Musculoskeletal diseases}

Physical examinations

Symptoms and signs of arthrosis and gout in knee, hip and hands Gout, chronic musculoskeletal pain, osteoarthritis, fractures, osteoporosis, Champs physical activity questionnaire

\section{Gastrointestinal diseases}

Disease specific questionnaires

Gastrointestinal symptoms (PAGI-SYM), de Bristol Stool From, Rome III criteria and Gastrointestinal Symptom Rating Scale (GSRS)

\section{Lifestyle and behaviour}

Lifestyle specific questionnaires

Food frequency questionnaire, health behavior, intrinsic motivation for movement, exposure and participation to interventions

Advanced measurements

Tri-axial accelerometry for 7 days, tailored health advise

\section{(Psycho-)social factors}

(Psycho-)social specific questionnaires

Socioeconomic status including education, employment, marital status, participation, social networks by use of exchange type name generator

Personality traits including Big Five (Goldberg) and Type D personality (DS14) 
assessments as described in Table 1. The detailed protocols for laboratory assessments are provided in the supplement.

\section{Physical examination}

Detailed protocols on the physical examination are provided in the supplements. Bio-electrical impedance spectroscopy (BIS) is used to estimate total body fat and fat free mass.

\section{Physical function and performance}

A 6-min fast walk test is conducted to assess general physical function. Details are presented in the supplement. Blood pressure and heart rate are measured at the start of the test and directly and $5 \mathrm{~min}$ after the end of the test (Omron 705IT, Omron, Japan). Physical function is also measured by use of a timed stand chair test (10 repetitions). Physical fitness is measured by use of an ECGguided sub-maximal exercise capacity test $(80 \%$ Bruce protocol; bicycle ergometer, General Electric, Ohio, USA). Muscle strength in the arms and legs is measured by isometric strength tests and handgrip strength is measured with a handgrip dynamometer (JAMAR Hydrolic Handdynamometer, SEHAN Corp, Korea-Biometrics Europe BV, Almere, the Netherlands).

\section{Medication use}

Participants are requested to bring all medication they use or a list from their pharmacists to the research center. During a medication interview generic name, dose and frequency are registered by trained staff.

\section{Blood pressure}

Blood pressure is measured in three ways: office blood pressure, ambulatory 24-h; and 7-days home blood pressure. Details about the measurements are presented in the supplement.

\section{General questionnaires}

All participants receive an extensive web-based questionnaire in which the following items are included: medical history, family history of diabetes and cardiovascular disease, socioeconomic status, smoking behavior, alcohol consumption (as part of the food frequency questionnaire (FFQ), see below), physical activity [30-33], quality of life (SF-36 [34, 35], EuroQol 5D) [36], activities of daily living (GARS-4) [37], birth weight and ethnicity. A short questionnaire on health consumption and productivity loss is used for economic evaluation.
Biobanking

Blood, two $24 \mathrm{~h}$ urine and morning urine samples are collected and stored at -80 degrees Celsius until use, as described in Table 1.

Measurements on T2DM and its classic complications

\section{Oral glucose tolerance test (OGTT)}

To determine glucose metabolism, all participants (except those who use insulin) undergo a standardized 7-point OGTT after an overnight fast. Blood samples are taken at baseline, and 15, 30, 45, 60, 90 and 120 min after ingestion of a $75 \mathrm{~g}$ glucose drink. For safety reasons, participants with a fasting glucose level above $11.0 \mathrm{mmol} / \mathrm{l}$, as determined by a finger prick, do not undergo the OGTT. Glucose metabolism is defined according to the WHO 2006 criteria into normal glucose tolerance (NGT), impaired fasting glucose (IFG), impaired glucose tolerance (IGT), and T2DM [38].

\section{Advanced glycation end products (AGEs)}

Skin autofluorescence is used to measure AGEs in the skin (AGEreader, Diagnoptic, The Netherlands).

\section{Electrocardiogram}

A resting 12-lead electrocardiogram (ECG; Mac 5500, GE Medical Systems, Milwaukee, Wisconsin, USA) and an ambulatory 24-h ECG (Fysiologic ECG Services BV, Zeist, the Netherlands) are recorded and archived electronically.

\section{Ankle brachial index}

The Omron VP2000 (Omron, Kyoto, Japan) is used to automatically determine ankle brachial index at the brachial artery of the left and right arm, and above the left and right ankle joint.

\section{Fundus photography}

To determine the presence of diabetic retinopathy, fundus photography of both eyes is performed and described in detail in the supplement.

\section{Peripheral vibration perception}

The peripheral vibration threshold is tested by use of a Horwell Neurothesiometer (Scientific Laboratory Supplies, Nottingham, UK). Vibration thresholds are tested 3 times at the distal phalanx of the hallux of the right and left foot. 


\section{Disease-specific questionnaires}

Specific questionnaires on diabetes and diabetes complications include a modified version of the Rose Questionnaire for the diagnosis of ischemic heart pain and intermittent claudication [39], the DN4 on neuropathic pain [40], the PAID Questionnaire on diabetes-related emotional distress [41], and a hypoglycemia questionnaire.

\section{Advanced measurements}

More advanced measures include microvascular assessment by use of nailfold microscopy and skin Laser-Doppler fluxmetry, cardiac and vascular ultrasound, applanation tonometry, an autonomic function test, 178-leads electrocardiogram (ECG), an electromyogram (EMG) assessment, an ECG-guided exercise test, and an abdominal fat measurement (ultrasound).

Measurements on emerging comorbidities of T2DM

\section{Neurological diseases}

A concise battery (30 min) of cognitive tests is used covering the domains of verbal memory (Verbal Word Learning [42], verbal intelligence (GIT word list) [43] attention and flexibility (Stroop test) [44], executive functioning (Concept Shifting test [45], fluency test [46] psychomotor speed (Letter-Digit Substitution test) [47] and general cognitive function (Mini-Mental State Examination, MMSE) [48]. When a cognitive disorder is suspected (MMSE $<24$, or $>1 / 6$ core tests in clinical range), additional screening takes place using the CAMDEX-N protocol [49]. Depression, suicide and anxiety symptoms are assessed by the Mini International Neuropsychiatric Interview (MINI) [50]. Hearing loss is identified with the Siemens HearCheck screener (Siemens, UK).

Disease-specific questionnaires Depressive symptoms and anxiety are screened with the Patient Health Questionnaire-9 (PHQ-9) [51] and the Generalized Anxiety Disorder 7-item scale (GAD-7) [52]. A migraine screening questionnaire is offered to all participants [53], screenpositive participants will complete a questionnaire based on the International Headache Society diagnostic criteria for migraine with and without aura [54]. In participants with active migraine, i.e., one or more attacks within the last 12 months, migraine severity will be assessed by the Migraine Disability Assessment (MIDAS) questionnaire [55]. Short questionnaires on hearing handicap (screening versions of the Hearing Handicap Inventory for the Elderly and the Hearing Handicap and Disability Inventory), hearing aid use (International Outcome Inventory for
Hearing Aids) and tinnitus (mini Tinnitus Questionnaire) are completed. Finally, a 4-item questionnaire on forgetfulness and the presence of eye diseases is included.

Advanced measurements Extensive ophthalmologic assessments are performed including visual acuity, optical coherence tomography (OCT), ocular pressure, Scheimpflug analysis, perimetry, corneal confocal microscopy, macula pigmentation and Dynamic Vessel Analysis (DVA).

\section{Respiratory diseases}

Lung function is assessed by spirometry (EasyOne ${ }^{\mathrm{TM}}$ spirometer, NDD Medical Technologies, Zurich, Switserland) and sleep-disordered breathing is assessed by portable respiratory monitoring (ApneaLink ${ }^{\mathrm{TM}}$, ResMed, USA). Portable respiratory monitoring is a non-invasive method for screening large groups of patients. Specific cardiopulmonary bioparameters as oxygen saturation, respiratory flow, pulse rate and body position are recorded. Nose and throat swabs are taken to assess microbial burden (presence and types of bacteria and viruses) of the airways. Exhaled breath samples are taken to analyze volatile organic compounds.

Disease-specific questionnaires A modified questionnaire of the American Thoracic Society (ATS-DLD-78-A) to assess respiratory complaints [56], the Epworth Sleepiness Scale to assess sleep related problems [57], and questionnaires on nicotine dependence, quitting smoking and acute infections are included.

\section{Musculoskeletal diseases}

Symptoms and signs of arthrosis and gout in knee, hip and hands are assessed by physical examination.

Disease-specific questionnaires Questionnaires on gout, chronic musculoskeletal pain, osteoarthritis, fractures, osteoporosis and a modified version of the Champs physical activity questionnaire are included.

\section{Gastrointestinal diseases}

Disease-specific questionnaires Gastrointestinal symptoms are assessed by the following questionnaires: Patient assessment of upper gastrointestinal symptom severity index (PAGI-SYM) [58], Bristol Stool Form [59], Diagnostic Criteria for Functional Gastrointestinal Disorders (Rome III criteria), and Gastrointestinal Symptom Rating Scale (GSRS). The ROME III criteria are developed by the Rome Foundation and are translated in Dutch. 
Lifestyle factors

\section{Lifestyle specific questionnaires}

Diet will be assessed by a tailor-made FFQ developed by use of the National FFQ Tool [60]. This FFQ assesses the intake frequency and amount of foods and nutrients for two different purposes: (1) etiological and prognostic research, and (2) to study determinants of dietary behavior and plan nutrition education activities. For the first purpose, the most important criterion for in- or excluding of foods in the FFQ is the explained variation in intake of certain nutrients, whereas for the second purpose, the contribution of foods to the intake of nutrients is most relevant. Validation of the FFQ against repeated 24-h recalls and biomarkers is currently in progress and will be described in a separate paper. Smoking and self-reported physical activity are assessed as described above. Alcohol consumption is assessed as part of the FFQ. Health behavior and beliefs are assessed by use of questionnaires including the following items: health behavior, intrinsic motivation for movement, exposure and participation to interventions.

\section{Advanced measurements}

Physical activity is measured by use of a tri-axial accelerometer that provides 7 days continuous wear (ActivPal, PAL Technologies Ltd, Glasgow, UK). For participants who would like to change their health behavior, a computer-tailored health advise program is offered. Participants are asked to fill out questions about their behaviors with regard to smoking, diet, physical activity, and alcohol use, as well as their motives for these behaviors. Based on their answers these participants receive a personalized on-line feedback about their behaviors and how to change them if relevant.

\section{(Psycho-)social factors}

\section{(Psycho-)social specific questionnaires}

Socioeconomic conditions are assessed by an extensive questionnaire which includes detailed information on marital status, educational level, occupational level, income level, work situation, poverty, material housing conditions, material working conditions, material neighborhood conditions and social participation and autonomy [61]. Social networks are assessed by use of an exchange type Name Generator [62]. Personality traits are assessed by the big five questionnaire by Goldberg [63] and the Type D personality questionnaire (DS14) [64].
Table 2 Future plans on advanced measurements within the Maastricht Study

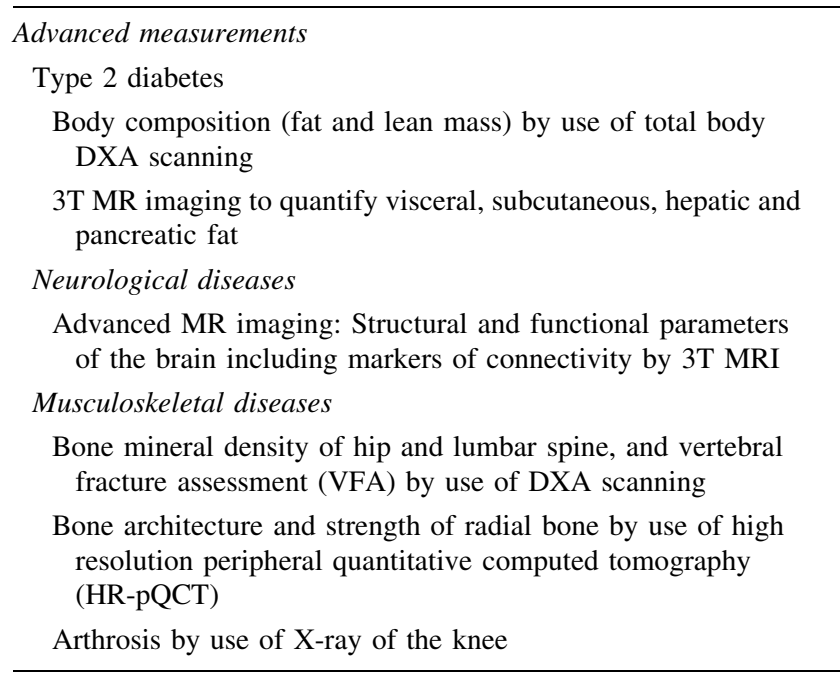

\section{Work in progress}

Table 2 presents the plans for additional advanced measurements in The Maastricht Study that include Dual X-ray Absorptiometry (DXA), MRI, X-ray and high resolution peripheral quantitative computed tomography (HR-pQCT) measurements. These measurements will be implemented in due time, and will be described in detail in subsequent papers.

\section{Morbidity and mortality}

Annual follow-up of disease incidence and mortality is in progress, comprising (1) collection of information from participants using an annual follow-up questionnaire specifically directed to chronic diseases that occurred in the past year; (2) linking of participant data to hospital and pharmacy records; and (3) collection of mortality data through existing up-to-date databases from Statistics Netherlands (CBS).

The main outcomes of the study, i.e., the incidence of T2DM, its classic complications and its 'emerging' comorbidities, are classified according to the ICD-10 as presented in Table 3.

The study region is characterized by a relatively high morbidity and mortality rate compared to Dutch national averages [65]. Based on these figures, it is anticipated that the main endpoints of the study will be reached within 5-10 years of follow-up. Even though prevalence and incidence rates of specific diseases and co-morbidities may deviate from other parts of the Netherlands, we expect that the etiological and pathogenic relations observed in The Maastricht Study can be generalized to (at least) ("westernized") Caucasians. Studies with similar designs (e.g., 
Table 3 Classic complications and emerging comorbidities of type 2 diabetes according to ICD-10 codes as main clinical outcomes of the Maastricht Study

\begin{tabular}{|c|c|}
\hline & ICD-10 code \\
\hline \multicolumn{2}{|l|}{ Classic complications of type 2 diabetes } \\
\hline \multicolumn{2}{|l|}{ Cardiovascular disease } \\
\hline Hypertension & I10-15 \\
\hline Ischaemic heart disease & I20-25 \\
\hline Cardiomyopathies & I42-43 \\
\hline Arrhythmias & I44, 47-49 \\
\hline Heart failure & $\mathrm{I} 50$ \\
\hline Unspecified heart disease & I51 \\
\hline Peripheral vascular disease & I73.9, I79.2 \\
\hline Cerebral artery disease & $\mathrm{I} 61,63,64$ \\
\hline Pulmonary embolism & I26 \\
\hline Deep venous thrombosis & I80.1-I80.3 \\
\hline \multicolumn{2}{|l|}{ Retinopathy } \\
\hline Diabetic retinopathy & $\mathrm{H} 36.0$ \\
\hline \multicolumn{2}{|l|}{ Neuropathy } \\
\hline Autonomic neuropathy & G99.0 \\
\hline Diabetic polyneuropathy & G63.2 \\
\hline Diabetic foot & S91 \\
\hline \multicolumn{2}{|l|}{ Nephropathy } \\
\hline Glomerular disorders in diabetes mellitus & N08.3 \\
\hline \multicolumn{2}{|l|}{ Emerging comorbidities of type 2 diabetes } \\
\hline \multicolumn{2}{|l|}{ Neurological diseases } \\
\hline Cognitive decline & not applicable \\
\hline Depression & F32 \\
\hline Migraine & G43.0-43.1 \\
\hline Hearing loss, tinnitus & H90, H93.1 \\
\hline \multicolumn{2}{|l|}{ Eye diseases } \\
\hline Senile cataract & $\mathrm{H} 25$ \\
\hline Diabetic cataract & $\mathrm{H} 28.0$ \\
\hline Glaucoma & H40.0-40.2 \\
\hline Macula edema & H35.8 \\
\hline Blindness and low vision & H54 \\
\hline \multicolumn{2}{|l|}{ Respiratory diseases } \\
\hline COPD & $\mathrm{J} 41,42,44$ \\
\hline Sleep apnea & G47.3 \\
\hline \multicolumn{2}{|l|}{ Musculoskeletal diseases } \\
\hline Gout & M10, E79 \\
\hline Osteoporosis & M80-82, 84 \\
\hline Fractures & $\begin{array}{l}\text { S02,22,32,42,52,62, } \\
72,82,92, \\
\text { T02,08,10, } \\
12,14.2,93.2\end{array}$ \\
\hline \multicolumn{2}{|l|}{ Gastrointestinal diseases } \\
\hline Irritable Bowel Syndrome & K58 \\
\hline NASH, NAFLD* & K76.0 \\
\hline
\end{tabular}

$N A S H$ non-alcoholic steatoHepatitis, $N A F L D$ non-alcoholic fatty liver disease the Rotterdam Study [66, 67] and the Hoorn Study [68, 69]) have generally supported these assumptions.

\section{Statistical power}

The vast amount of data collected within The Maastricht Study will enable various research questions to be addressed. For dichotomous outcomes, it will be possible to detect a relative risk of 1.25 in the T2DM and 1.38 in the non-diabetes subcohort if $10 \%$ of all participants have the relevant exposure and the 10 years incidence of the outcome of interest is $11 \%$ [assuming a type I error of $5 \%$ and a type II error of $20 \%$ (power $80 \%$ )]. The rates of most dichotomous and genetic exposures in The Maastricht Study are expected to vary generally between 10 and $20 \%$.

The sample size has been calculated to allow detection of a statistically significant modification of the effect of exposure on outcome risk by the state of diabetes. The use of continuous instead of dichotomous variables will enhance the power to an important extent, as will the use of multivariate modeling instead of stratified analysis.

\section{Status of the study}

From November 2010 until July 2013, a total of 3,000 individuals are enrolled and phenotyped in The Maastricht Study; enrolment is currently set at 2,000 participants per year. We expect that by the end of 2014 6,000 participants will be enrolled. Participants highly appreciate their participation in the Maastricht Study, as indicated by their evaluations which score 8.5 out of 10 ( $n \sim 450)$.

\section{Discussion}

The Maastricht Study is a unique innovative prospective population-based cohort study. To the best of our knowledge, The Maastricht Study will be the largest prospective cohort study worldwide that performs extensive phenotyping on T2DM and other chronic diseases in a population of up to 10,000 individuals, with oversampling of T2DM participants. Similar studies addressing T2DM, cardiovascular, neurological, respiratory, musculoskeletal and gastrointestinal diseases using advanced imaging techniques and extensive biobanking for detailed phenotyping and focusing on both determinants and relevant outcomes are currently not available. Therefore, The Maastricht Study fills a clear niche in international research. Furthermore, due to the relative isolation of the area under study, the study has some unique features: (1) The population is 
relatively stable and bound to the region, i.e., most citizens only relocate within the region or even within their municipality. This is a tremendous advantage in prospective studies, since participants will be relatively easy to trace after relocation. As a result, attrition due to loss to follow-up can be minimized. (2) The population has a homogeneous Caucasian background, which will enable extrapolation to other Caucasian populations in the Western world. (3) The prevalence and incidence of the main outcome variables of the study are relatively high in the study area when compared with other areas in the Netherlands, increasing the power to study these outcomes. (4) A wide range of differences in exposure of lifestyle and socioeconomic factors is present in the study area, ranging from for instance an un-healthy to a healthy lifestyle and a low to a high education level.

The Maastricht Study has some limitations. There is virtually no ethnic diversity in the study area, as nearly all inhabitants are of Caucasian origin. Hence, results of The Maastricht Study cannot be extrapolated to other ethnic groups. Furthermore, during the past decades the participation rates of longitudinal cohort studies in the Netherlands has declined. Therefore, commitment and satisfaction with study procedures are key factors for success in the recruitment and approach of participants, in order to safeguard not only their full participation in baseline measurements, but also their continued participation during follow-up. For recruitment, we apply direct mailings combined with public announcements, editorials in journals and magazines, as well as cooperation with locally active partners, such as the local professional soccer club in Maastricht (MVV). Reasons for declining participation as well as participants' satisfaction on the measurements are monitored.

Acknowledgments This study is supported by the European Regional Development Fund as part of OP-ZUID, the province of Limburg, the department of Economic Affairs of the Netherlands (grant 310.041), Stichting the Weijerhorst, the Pearl String Initiative Diabetes, the Cardiovascular Center Maastricht, Cardiovascular Research Institute Maastricht (CARIM), School for Nutrition, Toxicology and Metabolism (NUTRIM), Stichting Annadal, Health Foundation Limburg and by unrestricted grants from Janssen, Novo Nordisk and Sanofi. The regional association of General Practitioners (Zorg in Ontwikkeling (ZIO)) is gratefully acknowledged for their contribution to The Maastricht Study, enabling the invitation of individuals with T2DM by using information from their web-based electronic health record. Members of The Maastricht Study Group in alphabetic order: L.J. Anteunis, I.C.W. Arts, P. van Assema, W.H. Backes, T. Berendschot, A. Boonen, H. Bosma, H.P. Brunner- La Rocca, H.J. Crijns, P.C. Dagnelie, J.W. Dallinga, F. de Vries, H. de Vries, N.K. de Vries, N.H.T.M. Dukers-Muijrers, P.J. Emans, S. Evers, P.P. Geusens, A.P. Gorgels, R.M.A. Henry, D. Hilkman, C.J.P.A. Hoebe, A.P. Hoeks, P.A. Hofman, A.J. Houben, J.F.A. Jansen, M.A. Joore, M.E. Kooi, A. Koster, D. Kotz, S.P.J. Kremers, A.A. Kroon, A.A. Masclee, W.H. Mess, I. Mesters, J.W. Muris, C. Neef, N. Reijven, R.S. Reneman, J.P. Reulen, M. Sastry, H.H. Savelberg, P. Savelkoul, C.G. Schalkwijk, N.C. Schaper, F.J. van
Schooten, U. Schotten, J.S. Schouten, M.T. Schram, S.J.S. Sep, J.A. Staessen, C.D.A. Stehouwer, E.E. Stobberingh, M.P.J. van Boxtel, J.P. van den Bergh, C.P. van der Grinten, C.J. van der Kallen, S. van der Linden, M.C. van Dongen, T.A. van Geel, R.J. van Oostenbrugge, L. van Osch, F.H. Vanmolkot, F.R.J. Verhey, G.J. Wesseling, J.E. Wildberger, E.F.M. Wouters, L.J. Zimmerman (Maastricht University Medical Center+, Maastricht, the Netherlands) and T. Kuznetsova and T. Richart (University of Leuven, Leuven, Belgium), J. Denollet and F. Pouwer (University of Tilburg, Tilburg, the Netherlands) and G.J. Biessels (University of Utrecht, the Netherlands). Advisory Committee: M.J. Daemen (Amsterdam Medical Center, Amsterdam, the Netherlands), J.M. Dekker (VU University Medical Center, Amsterdam, the Netherlands), A. Hofman (Erasmus Medical Center, Rotterdam, the Netherlands), L.J. Launer (National Institutes of Health, National Institute on Aging, Bethesda, MD, USA), W. van Mechelen (VU University Medical Center, Amsterdam, the Netherlands, M. Stoll (Westfälische Wilhelms-Universität Münster, Münster, Deutschland), K. Stronks (Amsterdam Medical Center, Amsterdam, the Netherlands), J. Yudkin (Emeritus Professor of Medicine, University College London, Londen, UK).

Conflict of interest The authors declare that they have no conflict of interest.

\section{References}

1. Wild S, Roglic G, Green A, Sicree R, King H. Global prevalence of diabetes: estimates for the year 2000 and projections for 2030. Diabetes Care. 2004;27(5):1047-53.

2. WHO. The global burden of disease: 2004 update. 2008. http://www. who.int/healthinfo/global_burden_disease/GBD_report_2004update_ full.pdf.

3. Bloom DE, Cafiero ET, Jané-Llopis E, Abrahams-Gessel S, Bloom LR, Fathima S, Feigl AB, Gaziano T, Mowafi M, Pandya A, Prettner K, Rosenberg L, Seligman B, Stein AZ, Weinstein C. The global economic burden of noncommunicable diseases. Geneva: World Economic Forum; 2011.

4. Narayan KM, Boyle JP, Thompson TJ, Sorensen SW, Williamson DF. Lifetime risk for diabetes mellitus in the United States. JAMA. 2003;290(14):1884-90.

5. Clarke PM, Gray AM, Briggs A, Farmer AJ, Fenn P, Stevens RJ, et al. A model to estimate the lifetime health outcomes of patients with type 2 diabetes: the United Kingdom Prospective Diabetes Study (UKPDS) Outcomes Model (UKPDS no. 68). Diabetologia. 2004;47(10):1747-59.

6. Seshasai SR, Kaptoge S, Thompson A, Di Angelantonio E, Gao $\mathrm{P}$, Sarwar N, et al. Diabetes mellitus, fasting glucose, and risk of cause-specific death. N Engl J Med. 2011;364(9):829-41.

7. American Diabetes Association. Economic costs of diabetes in the U.S. in 2007. Diabetes Care. 2008;31(3):596-615.

8. Nolan CJ, Damm P, Prentki M. Type 2 diabetes across generations: from pathophysiology to prevention and management. Lancet. 2011;378(9786):169-81. doi:10.1016/s0140-6736(11)60614-4.

9. Weir GC, Bonner-Weir S. Five stages of evolving beta-cell dysfunction during progression to diabetes. Diabetes. 2004; 53(Suppl 3):S16-21.

10. Fu Z, Gilbert ER, Liu D. Regulation of insulin synthesis and secretion and pancreatic Beta-cell dysfunction in diabetes. Curr Diabetes Rev. 2013;9(1):25-53.

11. Sarwar N, Gao P, Seshasai SR, Gobin R, Kaptoge S, Di Angelantonio $\mathrm{E}$, et al. Diabetes mellitus, fasting blood glucose 
concentration, and risk of vascular disease: a collaborative metaanalysis of 102 prospective studies. Lancet. 2010;375(9733):221522. doi:10.1016/s0140-6736(10)60484-9.

12. Molitch ME, DeFronzo RA, Franz MJ, Keane WF, Mogensen CE, Parving HH, et al. Nephropathy in diabetes. Diabetes Care. 2004;27(Suppl 1):S79-83.

13. Icks A, Haastert B, Trautner C, Giani G, Glaeske G, Hoffmann F. Incidence of lower-limb amputations in the diabetic compared to the non-diabetic population findings from nationwide insurance data, Germany, 2005-2007. Exp Clin Endocrinol Diabetes. 2009;117(9):500-4. doi:10.1055/s-0029-1225333.

14. Resnikoff S, Pascolini D, Etya'ale D, Kocur I, Pararajasegaram $\mathrm{R}$, Pokharel GP, et al. Global data on visual impairment in the year 2002. Bull World Health Organ. 2004;82(11):844-51. doi:10.1590/S0042-96862004001100009.

15. Centers for Disease Control and Prevention. National diabetes fact sheet: national estimates and general information on diabetes and prediabetes in the United States, 2011. Atlanta, GA: U.S. Department of Health and Human Services, Centers for Disease Control and Prevention. 2011.

16. Wright JM, Musini VM. First-line drugs for hypertension. Cochrane Database of Syst Rev. 2009;3:CD001841. doi:10.1002/ 14651858.CD001841.pub2.

17. Baigent C, Keech A, Kearney PM, Blackwell L, Buck G, Pollicino $\mathrm{C}$, et al. Efficacy and safety of cholesterol-lowering treatment: prospective meta-analysis of data from 90,056 participants in 14 randomised trials of statins. Lancet. 2005;366(9493):1267-78. doi:10.1016/S0140-6736(05)67394-1.

18. Carnethon MR, Biggs ML, Barzilay J, Kuller LH, Mozaffarian D, Mukamal K, et al. Diabetes and coronary heart disease as risk factors for mortality in older adults. Am J Med. 2010;123(6):556e1-9. doi:10.1016/j.amjmed.2009.11.023.

19. Lee IM, Shiroma EJ, Lobelo F, Puska P, Blair SN, Katzmarzyk PT. Effect of physical inactivity on major non-communicable diseases worldwide: an analysis of burden of disease and life expectancy. Lancet. 2012;380(9838):219-29. doi:10.1016/ S0140-6736(12)61031-9.

20. Lollgen H, Bockenhoff A, Knapp G. Physical activity and allcause mortality: an updated meta-analysis with different intensity categories. Int J Sports Med. 2009;30(3):213-24. doi:10.1055/s0028-1128150.

21. Edwardson CL, Gorely T, Davies MJ, Gray LJ, Khunti K, Wilmot EG, et al. Association of sedentary behaviour with metabolic syndrome: a meta-analysis. PLoS ONE. 2012;7(4):e34916. doi:10.1371/journal.pone.0034916.

22. Wilmot EG, Edwardson CL, Achana FA, Davies MJ, Gorely T, Gray $\mathrm{LJ}$, et al. Sedentary time in adults and the association with diabetes, cardiovascular disease and death: systematic review and meta-analysis. Diabetologia. 2012. doi:10.1007/s00125-012-2677-z.

23. Bankoski A, Harris TB, McClain JJ, Brychta RJ, Caserotti P, Chen KY, et al. Sedentary activity associated with metabolic syndrome independent of physical activity. Diabetes Care. 2011;34(2):497-503.

24. Cooper AR, Sebire S, Montgomery AA, Peters TJ, Sharp DJ, Jackson N, et al. Sedentary time, breaks in sedentary time and metabolic variables in people with newly diagnosed type 2 diabetes. Diabetologia. 2012;55(3):589-99. doi:10.1007/s00125011-2408-x.

25. Healy GN, Wijndaele K, Dunstan DW, Shaw JE, Salmon J, Zimmet PZ, et al. Objectively measured sedentary time, physical activity, and metabolic risk: the Australian Diabetes, Obesity and Lifestyle Study (AusDiab). Diabetes Care. 2008;31(2):369-71. doi:10.2337/dc07-1795.

26. Koster A, Caserotti P, Patel KV, Matthews CE, Berrigan D, Van Domelen DR, et al. Association of sedentary time with mortality independent of moderate to vigorous physical activity. PLoS ONE. 2012;7(6):e37696. doi:10.1371/journal.pone.0037696.

27. Gallo V, Mackenbach JP, Ezzati M, Menvielle G, Kunst AE, Rohrmann S, et al. Social inequalities and mortality in Europeresults from a large multi-national cohort. PLoS ONE. 2012;7(7):e39013. doi:10.1371/journal.pone.0039013.

28. Espelt A, Borrell C, Roskam AJ, Rodriguez-Sanz M, Stirbu I, Dalmau-Bueno A, et al. Socioeconomic inequalities in diabetes mellitus across Europe at the beginning of the 21st century. Diabetologia. 2008;51(11):1971-9. doi:10.1007/s00125-008-1146-1.

29. www.nhg.org/standaarden/samenvatting/cardiovasculair-risico management.

30. van Keulen HM, Mesters I, Brug J, Ausems M, Campbell M, Resnicow K, et al. Vitalum study design: RCT evaluating the efficacy of tailored print communication and telephone motivational interviewing on multiple health behaviors. BMC Public Health. 2008;8:216. doi:10.1186/1471-2458-8-216.

31. van Keulen HM, Mesters I, Ausems M, van Breukelen G, Campbell M, Resnicow K, et al. Tailored print communication and telephone motivational interviewing are equally successful in improving multiple lifestyle behaviors in a randomized controlled trial. Ann Behav Med. 2011;41(1):104-18. doi:10. 1007/s12160-010-9231-3.

32. Resnicow K, McCarty F, Blissett D, Wang T, Heitzler C, Lee RE. Validity of a modified CHAMPS physical activity questionnaire among African-Americans. Med Sci Sports Exerc. 2003;35(9):1537-45. doi:10.1249/01.MSS.0000084419.64044.2B.

33. Harada ND, Chiu V, King AC, Stewart AL. An evaluation of three self-report physical activity instruments for older adults. Med Sci Sports Exerc. 2001;33(6):962-70.

34. McHorney CA, Ware JE Jr, Raczek AE. The MOS 36-Item ShortForm Health Survey (SF-36): II. Psychometric and clinical tests of validity in measuring physical and mental health constructs. Med Care. 1993;31(3):247-63.

35. Ware JESK, Kosinski M, et al. SF-36 health survey manual and interpretation guide. Boston, MA: New England Medical Center; 1993

36. Brooks R. EuroQol: the current state of play. Health Policy. 1996;37(1):53-72.

37. Suurmeijer TP, Doeglas DM, Moum T, Briancon S, Krol B, Sanderman R, et al. The Groningen Activity Restriction Scale for measuring disability: its utility in international comparisons. Am J Public Health. 1994;84(8):1270-3.

38. WHO. Definition and Diagnosis of diabetes mellitus and intermediate hyperglycemia. 2006. www.whoint/diabetes/pub lications/Definition\%20and\%20diagnosis\%20of\%20diabetes_new pdf.

39. Leng GC, Fowkes FG. The Edinburgh Claudication Questionnaire: an improved version of the WHO/Rose Questionnaire for use in epidemiological surveys. J Clin Epidemiol. 1992;45(10): 1101-9.

40. Bouhassira D, Attal N, Alchaar H, Boureau F, Brochet B, Bruxelle J, et al. Comparison of pain syndromes associated with nervous or somatic lesions and development of a new neuropathic pain diagnostic questionnaire (DN4). Pain. 2005;114(1-2):29-36. doi:10.1016/j.pain.2004.12.010.

41. Snoek FJ, Pouwer F, Welch GW, Polonsky WH. Diabetes-related emotional distress in Dutch and U.S. diabetic patients: crosscultural validity of the problem areas in diabetes scale. Diabetes Care. 2000;23(9):1305-9.

42. Van der Elst W, van Boxtel MP, van Breukelen GJ, Jolles J. Rey's verbal learning test: normative data for 1855 healthy participants aged 24-81 years and the influence of age, sex, education, and mode of presentation. J Int Neuropsychol Soc. 2005;11(3): 290-302. 
43. Luteijn F, Barelds DPH. GIT-2, Groninger intelligentietest 2. Handleiding. Amsterdam: Harcourt Test Publishers; 2004.

44. Van der Elst W, Van Boxtel MP, Van Breukelen GJ, Jolles J. The Stroop color-word test: influence of age, sex, and education; and normative data for a large sample across the adult age range. Assessment. 2006;13(1):62-79.

45. Van der Elst W, Van Boxtel MP, Van Breukelen GJ, Jolles J. The concept shifting test: adult normative data. Psychol Assess. 2006;18(4):424-32.

46. Van der Elst W, Van Boxtel MP, Van Breukelen GJ, Jolles J. Normative data for the Animal, Profession and Letter M Naming verbal fluency tests for Dutch speaking participants and the effects of age, education, and sex. J Int Neuropsychol Soc. 2006;12(1):80-9.

47. van der Elst W, van Boxtel MP, van Breukelen GJ, Jolles J. The letter digit substitution test: normative data for 1,858 healthy participants aged 24-81 from the Maastricht Aging Study (MAAS): influence of age, education, and sex. J Clin Exp Neuropsychol. 2006;28(6):998-1009.

48. Folstein MF, Folstein SE, McHugh PR. "Mini-mental state". A practical method for grading the cognitive state of patients for the clinician. J Psychiatr Res. 1975;12(3):189-98.

49. Derix T, Hijdra A. Camdex-N protocol. Cambridge Examination for Mental Disorders of the Elderly. 1992.

50. Sheehan DV, Lecrubier Y, Sheehan KH, Amorim P, Janavs J, Weiller E, et al. The Mini-International Neuropsychiatric Interview (M.I.N.I.): the development and validation of a structured diagnostic psychiatric interview for DSM-IV and ICD-10. J Clin Psychiatry. 1998;59(Suppl 20):22-33;quiz 4-57.

51. Kroenke K, Spitzer RL, Williams JB. The PHQ-9: validity of a brief depression severity measure. J Gen Intern Med. 2001; 16(9):606-13.

52. Spitzer RL, Kroenke K, Williams JB, Lowe B. A brief measure for assessing generalized anxiety disorder: the GAD-7. Arch Intern Med. 2006;166(10):1092-7. doi:10.1001/archinte.166.10.1092.

53. Launer LJ, Terwindt GM, Ferrari MD. The prevalence and characteristics of migraine in a population-based cohort: the GEM study. Neurology. 1999;53(3):537-42.

54. Headache Classification Subcommittee of the International Headache Society. The international classification of headache disorders. 2nd ed. Cephalalgia. 2004;24(Suppl 1):9-160.

55. Stewart WF, Lipton RB, Dowson AJ, Sawyer J. Development and testing of the Migraine Disability Assessment (MIDAS) Questionnaire to assess headache-related disability. Neurology. 2001;56(6 Suppl 1):S20-8.

56. Hurst JR, Vestbo J, Anzueto A, Locantore N, Mullerova H, TalSinger R, et al. Susceptibility to exacerbation in chronic obstructive pulmonary disease. N Engl J Med. 2010;363(12):1128-38. doi:10.1056/NEJMoa0909883.

57. Johns MW. A new method for measuring daytime sleepiness: the Epworth sleepiness scale. Sleep. 1991;14(6):540-5.

58. Rentz AM, Kahrilas P, Stanghellini V, Tack J, Talley NJ, de la Loge C, et al. Development and psychometric evaluation of the patient assessment of upper gastrointestinal symptom severity index (PAGI-SYM) in patients with upper gastrointestinal disorders. Qual Life Res. 2004;13(10):1737-49.

59. Lewis SJ, Heaton KW. Stool form scale as a useful guide to intestinal transit time. Scand J Gastroenterol. 1997;32(9):920-4. doi:10.3109/00365529709011203.

60. Molag ML, de Vries JH, Duif N, Ocke MC, Dagnelie PC, Goldbohm RA, et al. Selecting informative food items for compiling food-frequency questionnaires: comparison of procedures. $\mathrm{Br}$ J Nutr. 2010;104(3):446-56. doi:10.1017/S0007114510 000401.

61. Kersten P, Cardol M, George S, Ward C, Sibley A, White B. Validity of the impact on participation and autonomy questionnaire: a comparison between two countries. Disabil Rehabil. 2007;29(19):1502-9. doi:10.1080/09638280601030066.

62. McCallister L, Fischer CS. A procedure for surveying personal networks. Sociol Methods Res. 1978;7(2):131-48.

63. Goldberg LR. An alternative "description of personality": the big-five factor structure. J Pers Soc Psychol. 1990;59(6):1216-29.

64. Denollet J. DS14: standard assessment of negative affectivity, social inhibition, and Type D personality. Psychosom Med. 2005;67(1):89-97. doi:10.1097/01.psy.0000149256.81953.49.

65. Lamberts PHG, Steenbakkers M, Thijssen NHB, Backus-Mujakovic S, de Vreede JJM, Hajema KJ, Poos MJJC. Een gezonde kijk op Zuid-Limburg. Regionale Volksgezondheid Toekomst Verkenning 2010. GGD Zuid-Limburg; 2010.

66. Hofman A, Grobbee DE, de Jong PT, van den Ouweland FA. Determinants of disease and disability in the elderly: the Rotterdam Elderly Study. Eur J Epidemiol. 1991;7(4):403-22.

67. Dehghan A, Kardys I, de Maat MP, Uitterlinden AG, Sijbrands EJ, Bootsma $\mathrm{AH}$, et al. Genetic variation, C-reactive protein levels, and incidence of diabetes. Diabetes. 2007;56(3):872-8. doi:10.2337/db06-0922.

68. Mooy JM, Grootenhuis PA, de Vries H, Valkenburg HA, Bouter LM, Kostense PJ, et al. Prevalence and determinants of glucose intolerance in a Dutch Caucasian population. The Hoorn Study. Diabetes Care. 1995;18(9):1270-3.

69. Schram MT, Kostense PJ, Van Dijk RA, Dekker JM, Nijpels G, Bouter LM, et al. Diabetes, pulse pressure and cardiovascular mortality: the Hoorn Study. J Hypertens. 2002;20(9):1743-51. 